\title{
Surgical Site Infections Incidence, their Predictors and Causative Organisms in a Teaching Hospital
}

\author{
Ali Ahmad Awad Rawabdeh ${ }^{*}$, Abdul Rahman Saleh Al Mulhim ${ }^{2}$ and Zahid Ullah Khan ${ }^{3}$ \\ ${ }^{1}$ Family and Community Medicine Department, College of Medicine, King Faisal University, Al-Ahsa, Saudi Arabia \\ ${ }^{2}$ Department of Surgery, College of Medicine, King Faisal University, Al-Ahsa, Saudi Arabia \\ ${ }^{3}$ Peterborough \& Stamford Hospitals NHS Trust, Peterborough, PE3 9GZ, United Kingdom
}

\begin{abstract}
Purposes: Nosocomial infections (NCIs) are infections that generally occur 48 hours after hospitalization. Surgical site infections (SSIs) are the major contributor to patient morbidity, health care costs and death. The rational for this study was to assess the frequency of NCIs in surgical wards and investigate possible predictors for SSIs.

Methods: It was an observational and prospective study for the purpose of providing structured opportunities for Hospital administration and health professionals in countering SSIs. The total number of patients were 1611 including Saudis and non-Saudi nationals. Each patient was followed up from the time of admission until discharge (with a maximum period of 30 days postoperatively). Surgical wounds were inspected at the time of the first dressing and weekly thereafter for 30 days. Also, swabs from a deeper part of the wound were taken from the infected surgical sites, and routinely from the surface of non-infected sites. The specimens were gram stained and examined for the presence of organisms (cultured aerobically and anaerobically).

Findings: The main findings were: SSIs causative organisms were Staphylococcus aureus (25\% incidence) followed by Echeriashia coli ( $23 \%$ incidence). The incidence rate of surgical site infections was $11.4 \%$. The presences of co-morbidities were a risk factor for SSIs in this study and a higher level of education was related to decreases in SSIs.

Recommendations: This article recommended proper nursing care, sterilization and disinfection of instruments and equipment with careful handling of intensive procedures to control infection which will improve the efficiency and quality of surgical care.
\end{abstract}

\section{Introduction}

Surgical site infections (SSIs) are considered to be the most common nosocomial infections (NCIs) in surgical patients accounting for $38 \%$ of all NCIs which not only causes an increase in patient morbidity but can also prolong hospital stay and thereby increase health care costs $[1,2]$. SSIs are the second most common cause of hospital-acquired infections [3]. The risk factors responsible for SSIs are largely modifiable [4] - the occurrence of SSIs depend on a number of factors including patient health status (pre-morbid conditions such as diabetes and hypertension), length of hospital stay and patient level of education, the type of surgical intervention performed, sterilization procedures and use of any pre-operative antibiotics and the quality of the facility of postoperative surgical care. For this purpose it is important to have accurate data on SSIs in order to optimize patient health outcome and to prioritize healthcare funding. Studies from Saudi Arabia and other developing countries utilized data forms available through National Nosocomial Infection Surveillance System (NNIS) recommended by the Centers for Disease Control and Prevention (CDC) [5].

The main objective of this study was to investigate the possible predictors for SSIs with identification of the etiological pathogens at Surgery Department of in Al Hassa, Saudi Arabia. This study was expected to initiate quality performance indicators to surgeons with regards to infections, improve the effectiveness and the quality of surgical care, use of clinical and administrative data (indicators) to improve patient outcomes, examine the efficacy of infection control program available at $\mathrm{KFH}$, reducing costs by avoiding infections, educating health workers and medical students on the potential risks, preventive measures to be taken, and cost containment.

\section{Materials and Methods}

This research conducted a cross-sectional prospective study among patients undergoing surgical procedures at the study area during the period from April 1st 2013 to May 28th 2014. The study area is a secondary care hospital that serves the a population of 1.5 million in Al Hassa, Eastern province of Saudi Arabia, The hospital has 400 beds, with four wards dedicated to general surgery (150 surgical beds) and the average length of stay for each surgical patient is about 3.9 days as shown in Table 1 . This study was approved by the Ethical Committee of King Faisal University and the area of the study.

All patients admitted to the surgical wards for more than one day and who had a surgical procedure in the surgical units were included in this study. Patients who were transferred from other hospitals or other units after surgical procedures were excluded from this study along with those whose length of stay was less than one day. Information collected included:

Socio-demographics and health data of patients: age, gender, nationality, residence, educational status, and the presenting diagnosis.

*Corresponding Author: Dr. Ali Ahmad Awad Rawabdeh, Family and Community Medicine Department, College of Medicine, King Faisal University, Al-Ahsa, Saudi Arabia, E-mail: aalrawabdeh@kfu.edu.sa

Citation: Rawabdeh AAA, Al Mulhim ARS, Khan ZU (2016) Surgical Site Infections Incidence, their Predictors and Causative Organisms in a Teaching Hospital . Int J Community Fam Med 1: 104. doi: https://doi.org/10.15344/24563498/2016/104

Copyright: (C) 2016 Rawabdeh et al.This is an open-access article distributed under the terms of the Creative Commons Attribution License, which permits unrestricted use, distribution, and reproduction in any medium, provided the original author and source are credited. 
Citation: Rawabdeh AAA, Al Mulhim ARS, Khan ZU (2016) Surgical Site Infections Incidence, their Predictors and Causative Organisms in a Teaching Hospital Int J Community Fam Med 1: 104. doi: https://doi.org/10.15344/2456-3498/2016/104

Page 2 of 6

\begin{tabular}{|l|l|l|l|l|l|l|}
\hline Indicator & $\begin{array}{l}\text { Physician / } \\
\text { population (10,000) }\end{array}$ & $\begin{array}{l}\text { Nurse/ } \\
\text { population } \\
(10,000)\end{array}$ & $\begin{array}{l}\text { Allied health personnel/ } \\
\text { population (10,000) }\end{array}$ & $\begin{array}{l}\text { Pharmacist/ } \\
\text { population (10,000) }\end{array}$ & $\begin{array}{l}\text { Average length } \\
\text { of stay/patient } \\
\text { rate/100 population }\end{array}$ & 3.9 \\
\hline Rate/Ratio & 11.2 & 20.3 & 3.2 & 0.93 & $\begin{array}{l}\text { Average increase rate } \\
\text { of surgery }\end{array}$ & $\begin{array}{l}\text { Nurse/ } \\
\text { physician }\end{array}$ \\
\hline Indicator & $\begin{array}{l}\text { Average visit / } \\
\text { person }\end{array}$ & Bed rotation & Occupancy Rate & 15.4 & 2.5 \\
\hline Rate/Ratio & 2.2 & $54.2 \%$ & $90 \%$ & & $5 \%$ \\
\hline
\end{tabular}

Table 1: General demographics of the study population.

Co-morbidity of patients: the presence of comorbid disease condition (e.g. diabetes and hypertension) was investigated through revision of the patients' health records and through the pre-operative assessments by the surgical and anesthesia teams.

Surgical intervention data: the type of surgical interventions, use of pre-operative antibiotics (type and duration), duration of surgery, American Society of Anesthesiologist (ASA) score, wound drainage and type of operation classified as clean, clean-contaminated, contaminated and dirty based on the criteria of the (CDC) $[7,8]$.

Clinical evaluation of wound: Each patient was followed up from the time of admission until 30 days post discharge from hospital. Surgical wounds were inspected at the time of the first dressing and weekly thereafter for 30 days in the outpatient departments. SSIs were diagnosed according to the guidelines of the CDC [8] and infection would be regarded as SSI if it occurs within 30 days of procedure and has at least one of the following; purulent drainage from the wound, pain or tenderness, localized swelling, redness, malodor, fever.

Swabs from a deeper part of the wound were taken from the infected surgical sites, and routinely from the surface of non-infected sites on weekly basis in the outpatient department and temperature, color of discharge and status of the surgical scar were recorded in terms of being infected or not. The specimens were gram stained and examined for the presence of organisms and cultured in commercial blood agar both aerobically and anaerobically and in cooked meat broth. Gram staining was used for organisms' identification from infected surgical wounds. Bacterial isolates were identified and tested for antimicrobial susceptibility. Weekly follow-up visits were arranged for the patient to assess the surgical site following discharge from hospital.

A notable limitation to this study can be that aspirates were not obtained from deep wounds and swabs are not reliable for deeper wounds infections which could have potentially caused lower incidence of SSIs.

Data entry and analysis was carried out using SPSS version 16.0 (SPSS Inc., Chicago IL, USA). Categorical data were reported in frequency, proportion and percentage, univariate analysis with estimation of Odds ratio and 95\% confidence interval (CI), Chisquare, and $\mathrm{Z}$ test for proportions tests of significance were used for comparisons. Regression analysis: Hierarchical logistic regression analysis was generated to determine whether socio-demographics including age, gender, education, chronic morbidity, and body mass index (BMI), peri-operative conditions including type of surgery, ASA score, and wound class and postoperative variables namely total operative time, drain, ICU admission, length of stay in ICU and total length of hospital stay are potential predictors for the development of SSIs.
Permission was obtained from both King Faisal University and the area of the study to conduct the study in advance. Completed Informed Consent forms were obtained and data confidentiality was maintained throughout.

\section{Results}

The total number of patients included and followed up were 1611, all of which were admitted for more than 48 hours, and 41 cases were transferred out to more specialized centers $(n=27)$ or private hospitals health $(\mathrm{n}=14)$. Among patients included, the ages ranged from 3 years to 78 years with a median of 26.5 (mean of $29.1 \pm 16.2$ ) years. Males constituted $51.7 \%$ of cases, and $94.0 \%$ were Saudi nationals (amongst which $51.4 \%$ were resident of urban areas) and $55.9 \%$ with education of $<9$ years formal schooling. Chronic diseases and conditions were reported in $12 \%$ of the total patients with diabetes and hypertension (two of the most frequently encountered conditions in the region).

Table 2 demonstrates the operative procedures conducted by type, site and the distribution of SSIs in relation to surgical procedures. Out of 1611 operative procedures performed, abdominal-pelvic operations accounted for $51.2 \%$, and SSIs were diagnosed in $183(11.4 \%)$ patients. SSIs were higher in abdominal-pelvic surgical procedures (12.6\%) as compared to extra-abdominal procedures (10.1\%) (Odds ratio, $\mathrm{OR}=1.29, \mathrm{CI}=0.94-1.78)$ with the highest risk associated with open appendectomies and laparotomies.

Table 3 depicts the distribution of SSIs according to the sociodemographics, the presence of pre-operative co-morbid conditions and BMI. Males, aged $\geq 60$ years were more prone to SSIs (OR age $=1.66, \mathrm{CI}=1.01-2.71, \mathrm{P}=0.011$ and $\mathrm{OR}$ gender $1.40, \mathrm{CI}=1.02-1.93$, $\mathrm{P}=0.012$ ).

Patient nationality and residence did not significantly increase the risk for SSIs. The presence of pre-operative co-morbid disease conditions posed a significant higher risk for the SSIs $(\mathrm{OR}=3.12$, $\mathrm{CI}=2.12-4.60, \mathrm{P}=0.001)$ without assigning this to any particular disease. Those with education of $\geq 12$ years were less prone to SSIs as compared to other educational categories $(\mathrm{OR}=0.37, \mathrm{P}=0.001)$. Those who were overweight and obese were at higher risk for SSIs than nonobese where the risk for SSIs for obese was $(\mathrm{OR}=1.85, \mathrm{CI}=1.19-2.86$, $\mathrm{P}=0.001)$.

Table 4 shows the risk of SSIs in relation to the included perioperative and operative variables included. Out of 516 emergency surgical interventions, 124 (24.0\%) cases developed SSIs compared to only $5.4 \%$ for elective surgeries $(\mathrm{OR}=5.55, \mathrm{CI}=3.94-7.84, \mathrm{P}=0.001)$. Pre-operative antibiotics were administered to 1331 patients in the form of cefotaxime $(29.7 \%)$, ampicloxacillin $(20.3 \%)$, ceftriaxonemetronidazole (18.8\%), ampicloxacillin-gentamicin (8.5\%), ampicloxacillin-metronidazole (7.0\%), gentamicin (5.9\%), ceftriaxoneampicloxacillin (5.1\%), and ciprofloxacin (4.7\%). The duration 
Citation: Rawabdeh AAA, Al Mulhim ARS, Khan ZU (2016) Surgical Site Infections Incidence, their Predictors and Causative Organisms in a Teaching Hospital . Int J Community Fam Med 1: 104. doi: https://doi.org/10.15344/2456-3498/2016/104

Page 3 of 6

\begin{tabular}{|c|c|c|c|}
\hline Procedures & $\begin{array}{c}\text { Total }(\mathrm{N}=1611) \\
\text { No. }(\%)\end{array}$ & $\begin{array}{c}\text { Surgical site infections }(\mathrm{N}=183 \\
\text { No. }(\%)\end{array}$ & Incidence (\%) \\
\hline Abdominal surgery: & $825(51.2)$ & $104(56.8)$ & 12.6 \\
\hline Open appendectomy & $354(22.0)$ & $47(25.7)$ & 13.3 \\
\hline Splenectomy * & $43(2.7)$ & $9(4.9)$ & 20.9 \\
\hline Colon resection/fixation & $11(0.7)$ & $3(1.6)$ & 27.3 \\
\hline Laparotomies ${ }^{* *}$ (trauma/acute abdomen) & $56(3.5)$ & $21(11.5)$ & 37.5 \\
\hline Open cholecystectomies & $13(0.8)$ & $6(3.3)$ & 46.2 \\
\hline Lap banding & $23(1.4)$ & $6(3.3)$ & 26.1 \\
\hline Paraumbilical hernia & $113(7.0)$ & $5(2.7)$ & 4.4 \\
\hline Laparoscopic cholecystectomy & $189(11.7)$ & $5(2.7)$ & 2.6 \\
\hline Laparoscopic appendectomy & $23(1.4)$ & $2(1.1)$ & 8.7 \\
\hline - Other surgical procedures: & $786(48.8)$ & $79(43.2)$ & 10.1 \\
\hline Hernioplasty & $202(12.5)$ & $6(3.3)$ & 3.0 \\
\hline Hemorrhoids & $87(5.4)$ & $1(0.5)$ & 1.1 \\
\hline Anal fissures/fistulae & $31(1.9)$ & $2(1.1)$ & 6.5 \\
\hline Peri-anal abscesses & $21(1.3)$ & $3(1.6)$ & 14.3 \\
\hline Open breast biopsy & $42(2.6)$ & $7(3.8)$ & 16.7 \\
\hline Breast lumpectomies/mastectomies & $34(2.1)$ & $9(4.9)$ & 26.5 \\
\hline Burn management & $98(6.0)$ & $21(11.5)$ & 21.4 \\
\hline Diabetic foot & $89(5.5)$ & $23(12.6)$ & 25.8 \\
\hline Vascular access & $49(3.0)$ & $3(1.6)$ & 6.1 \\
\hline Plastic cosmetic & $31(1.9)$ & $1(0.5)$ & 3.2 \\
\hline Skin lesions & $75(4.7)$ & $1(0.5)$ & 1.3 \\
\hline Thyroid & $27(1.7)$ & $2(1.1)$ & 7.4 \\
\hline
\end{tabular}

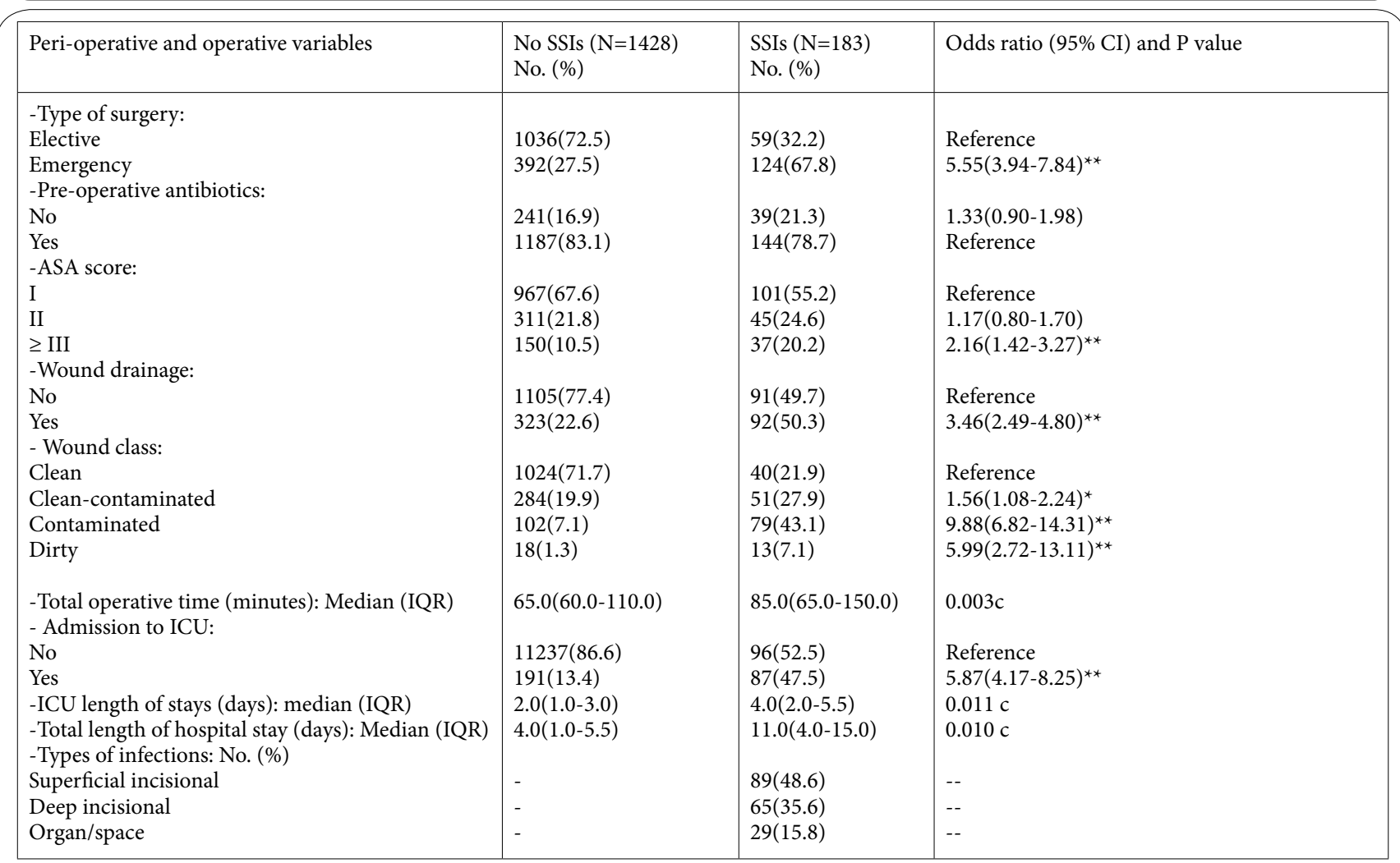

Table 3: Peri-operative/operative characteristics of the included surgical patients classified according to the presence of SSIs.

intake ranged from 6 hours to 7 days, median of 3.0 days. The risk of SSIs among those not receiving pre-operative antibiotics was higher without being statistical significant $(\mathrm{P}=0.136)$. The table also shows the distribution of the included patients according to the ASA score, $22.1 \%$ within ASA II, $11.6 \%$ with III or more, where the risk of SSIs increased proportionality with ASA scores from $(\mathrm{OR}=1.17$ for 2 to 2.16 for $\geq \operatorname{III}(\mathrm{P}=0.001)$. Out of 415 wounds with drainage,
$22.2 \%$ developed SSIs compared to those without drainage ( $\mathrm{OR}=3.46$, $\mathrm{CI}=2.49-4.80, \mathrm{P}=0.001)$. Wounds encountered were classified as $1064(66.0 \%)$ clean, $356(22.1 \%)$ clean-contaminated, $160(10.0 \%)$ contaminated and $31(1.9 \%)$ as dirty. The risk of SSIs was significantly higher among contaminated and dirty categories $(\mathrm{OR}=9.88, \mathrm{P}=0.001$ for contaminated and $\mathrm{OR}=5.99, \mathrm{P}=0.001$ for dirty wounds). The risk for contaminated-dirty wounds was significantly higher compared to 
Citation: Rawabdeh AAA, Al Mulhim ARS, Khan ZU (2016) Surgical Site Infections Incidence, their Predictors and Causative Organisms in a Teaching Hospital . Int J Community Fam Med 1: 104. doi: https://doi.org/10.15344/2456-3498/2016/104

Page 4 of 6

\begin{tabular}{|l|l|l|}
\hline Organisms & $\begin{array}{l}\text { Number } \\
(\mathrm{N}=183)\end{array}$ & Percentage \\
\hline & & \\
\hline - Eschershia coli & 42 & 23.0 \\
- Pseudomonas aergonisa & 36 & 19.7 \\
Staphylococcus & 47 & 25.7 \\
auerus & 27 & 14.8 \\
epidermis & 6 & 3.3 \\
coagulase negative & 5 & 2.7 \\
MRSA & 6 & 3.3 \\
-Enterobacter & 12 & 6.6 \\
Fecalis & 9 & 4.9 \\
- Streptococci & 9 & 4.9 \\
Hemolytic & 6 & 3.3 \\
Viridans & 3 & 1.6 \\
- Acintobacter baumanni & 6 & 3.3 \\
- Aeromonas species & 1 & 0.5 \\
- Citrobacter freundi & 1 & 0.5 \\
- Candida & 2 & 1.1 \\
- Samonella SERO & 1 & 0.5 \\
- Pseudomonas aerogonisa + pseudomonas & 3 & 1.3 \\
fluores & & \\
- Psudeomonas + Echeriashia coli & 16 & 8.7 \\
- Other* & 5 & 2.7 \\
\hline
\end{tabular}

Table 4: Organisms encountered in SSIs in general surgery at the study area 2011. clean and clean-contaminated wounds $(\mathrm{OR}=11.02$, C.I=7.69-15.79, $\mathrm{P}=0.001)$. The types of wound infections were $48.6 \%$ superficial incisional, $35.6 \%$ were deep incisional and $15.8 \%$ were organspace infections. The total operative time ranged form 35 minutes to 6.5 hours with a median of 70.0 minutes (interquartile range, $\mathrm{IQR})=60.0-140.0$ minutes). Those with SSIs underwent a relatively prolonged surgery $(\mathrm{P}=0.003)$. Out of all procedures $278(17.3 \%)$ were admitted to intensive care units, with a total length of stay ranged from 6 hours to 9 days, median of 2.0 days and IQR=2.0. SSIs were encountered at a higher rate among those admitted to ICUs with prolonged duration of stay. The total hospital stay ranged form 1.0 to 16 days with a median of 4.0 and IQR of 5.0 days. Table 4 displays the organisms encountered from the SSIs as revealed by culture. Staphylococcus species were the most commonly isolated organisms (25.7\%), MRSA was only encountered in 6 cases followed by Eschershia coli (23.0\%), and Pseudomonas aerognonisa (19.7\%), Pseudomonas + Eschershia coli (8.7\%) and Enterobacter species (6.6\%).

Table 5 displays the distribution of the causative organisms in relation to operation sites. Pseudomonas + Eschershia coli were both isolated form abdominopelvic wounds, while Staphylococcus species, Streptococcus and Entrobacter from extra abdominal surgical sites.

\begin{tabular}{|c|c|c|c|c|c|c|c|}
\hline Procedures & $\begin{array}{l}\text { Staphylococcus } \\
(\mathrm{N}=47)\end{array}$ & $\begin{array}{l}\text { Pseudomonas } \\
(\mathrm{N}=36)\end{array}$ & $\begin{array}{l}\text { Eschershia } \\
\text { coli }(\mathrm{N}=42)\end{array}$ & $\begin{array}{l}\text { Streptococcai } \\
(\mathrm{N}=9)\end{array}$ & $\begin{array}{l}\text { Enterobacter } \\
(\mathrm{N}=12)\end{array}$ & $\begin{array}{l}\text { Acintobacter } \\
\text { baumanni } \\
(\mathrm{N}=6)\end{array}$ & $\begin{array}{l}\text { Psudomonas } \\
+ \text { Eschershia } \\
\text { coli } \\
(\mathrm{N}=16)\end{array}$ \\
\hline - Abdominal surgery: no. (\%) & $10(21.3)$ & $26(72.2)$ & $38(90.5)$ & - & $3(25.0)$ & $3(50.0)$ & $13(81.3)$ \\
\hline Open appendectomy & 6 & 4 & 13 & - & 3 & 1 & 11 \\
\hline Splenectomy & 1 & 4 & 3 & - & - & - & - \\
\hline Colon resection/fixation & - & 3 & - & - & - & - & - \\
\hline Laparotomies (trauma/acute abdomen) & 1 & 9 & 8 & - & - & 2 & - \\
\hline Open cholecystomies & - & 2 & 4 & - & - & - & 2 \\
\hline Lap banding & - & 1 & 4 & - & - & - & - \\
\hline Para-umbilical hernia & 2 & 1 & 1 & - & - & - & - \\
\hline Laparoscopic cholecystectomy & - & 2 & 3 & - & - & - & - \\
\hline Laparoscopic appendectomy & - & - & 2 & - & - & - & - \\
\hline - Other surgical procedures: no. (\%) & $37(78.7)$ & $10(27.8)$ & $4(9.5)$ & $9(100.0)$ & $9(75.0)$ & $3(50.0)$ & $3(18.8)$ \\
\hline Hernioplasty & 3 & 2 & 1 & - & - & - & - \\
\hline Hemorrhoids & 1 & - & - & - & - & - & - \\
\hline Anal fissures/fistulae & - & - & 1 & - & 1 & - & - \\
\hline Peri-anal abscesses & - & - & 2 & 1 & - & - & - \\
\hline Open breast biopsy & 4 & - & - & 3 & - & - & - \\
\hline Breast lumpectomies/mastectomies & 6 & - & - & 3 & - & - & - \\
\hline Burn management & 9 & 5 & - & - & 2 & 3 & 2 \\
\hline Diabetic foot & 11 & 3 & - & - & 3 & - & 1 \\
\hline Vascular access & - & - & - & 1 & 2 & - & - \\
\hline Plastic cosmetic & 1 & - & - & - & - & - & - \\
\hline Skin lesions & 1 & - & - & - & 1 & - & - \\
\hline Thyroid & 1 & - & - & 1 & - & - & - \\
\hline
\end{tabular}

Table 5: Distribution of causative microorganisms in relation to surgical procedures among patients with SSIs. 
Citation: Rawabdeh AAA, Al Mulhim ARS, Khan ZU (2016) Surgical Site Infections Incidence, their Predictors and Causative Organisms in a Teaching Hospital Int J Community Fam Med 1: 104. doi: https://doi.org/10.15344/2456-3498/2016/104

Page 5 of 6

\begin{tabular}{|c|c|c|c|c|}
\hline \multirow{2}{*}{ Steps } & \multirow[t]{2}{*}{ Variables entered } & \multicolumn{3}{|c|}{ Odds ratio (95\% confidence intervals) } \\
\hline & & Model 1 & Model 2 & Model 3 \\
\hline 1- Basic patients characteristics & $\begin{array}{l}\text { - Age ( } \geq 60 \text { years) } \\
\text { - Gender (female) } \\
\text { - Education ( } \geq 12 \text { years) } \\
\text { - Chronic morbidity (yes) } \\
\text { - Body mass index ( } \geq 30)\end{array}$ & $\begin{array}{l}1.62(1.02-2.54)^{\star} \\
1.39(1.08-1.79)^{\star} \\
1.41(1.23-1.76)^{\star} \\
3.11(2.11-4.58)^{\star *} \\
1.82(1.13-2.94)^{\star *}\end{array}$ & $\begin{array}{l}1.39(0.83-2.33) \\
1.34(0.81-2.22) \\
1.33(0.93-1.92) \\
1.79(1.17-2.74)^{\star *} \\
1.54(1.31-1.93)^{\star}\end{array}$ & $\begin{array}{l}1.31(0.81-2.13) \\
1.29(0.78-2.13) \\
1.30(0.91-1.86) \\
1.54(1.31-1.93)^{\star} \\
1.41(0.98-2.04) \\
2.18(1.42-3.34)^{\star *}\end{array}$ \\
\hline 2- Peri-operative conditions & $\begin{array}{l}\text { - Type of surgery (emergency) } \\
\text { - ASA score }(\geq 3) \\
\text { - Wound class (contaminated-dirty) }\end{array}$ & & $\begin{array}{l}4.79(3.91-5.87)^{\star *} \\
2.18(1.28-3.72)^{\star *} \\
8.87(6.21-12.66)^{\star *}\end{array}$ & $\begin{array}{l}1.83(1.24-2.70)^{\star} \\
5.62(4.08-7.73)^{\star *}\end{array}$ \\
\hline 3- Post-operative conditions & $\begin{array}{l}\text { - Operative time ( } \geq 90 \text { minutes) } \\
\text { - ICU admission (yes) } \\
\text { - Presence of drain } \\
\text { - ICU length of stay ( } \geq 2 \text { days) } \\
\text { - Total hospital length of stay ( } \geq 6 \text { days). }\end{array}$ & & & $\begin{array}{l}1.98(1.34-2.93)^{\star} \\
3.19(2.22-4.59)^{\star *} \\
3.02(2.09-4.37)^{\star *} \\
1.39(0.83-2.33) \\
1.34(0.81-2.22) \\
11.41\end{array}$ \\
\hline Constant & & 14.08 & 13.25 & .238 \\
\hline & & .195 & .216 & 34.71 \\
\hline & & 28.17 & 31.32 & 0.091 \\
\hline Significance & & 0.003 & 0.005 & \\
\hline
\end{tabular}

Table 6: Hierarchical multivariate regression analysis models of risk factors for SSIs at the study area 2011.

$R^{2}$ ! using Nagelkerke likelihood ratio, ${ }^{\star} P<0.05,{ }^{*} P<0.01$

Table 6 depicts the results of the generated multivariate hierarchical regression analysis models. The initial model shows that out of the included basic patient characteristics, the presence of chronic comorbidity and BMI $(\geq 30)$ were significant predictors for SSIs $\Delta \chi^{2}=$ $28.17, \mathrm{R}^{2}=.195, \mathrm{P}=0.003$. In the second model, with forced inclusion of peri-operative conditions, the effect of basic patient characteristics was attenuated with type of surgery, ASA score of $\geq$ III, and wound class (contaminated-dirty) were the positive predictors for SSIs, $\Delta \chi^{2}$ $=31.32, \mathrm{R}^{2}=.216, \mathrm{P}=0.005$. In the final model, the presence of chronic co-morbidity were included to predict the incidence of SSIs, ASA score was attenuated, the significant predictors for the development of SSIs including wound class (contaminated-dirty), longer operative time ( $\geq 90$ minutes), ICU admission and the presence of wound drain $\left(\Delta \chi^{2}=34.71, \mathrm{R}^{2}=.238, \mathrm{P}=0.091\right)$. Hospital stay and length of stay in the ICU were not significant predictors for the development of SSIs in the final model.

\section{Discussion}

SSIs are the second most common type of adverse events occurring in hospitalized patients following surgery and are one of the most common surgical complications [10]. The main focus of this study was to find out the incidence and risk factors associated with SSIs in surgical wards. The SSIs incidence in this study was $11.4 \%$ (183 SSI cases) as compared to previous studies of $6 \%$ Shahane V et al. $3.7 \%$ [11], for Atif ML et al. 6.8\% [12], for Khairy GA et al. [6], with the highest incidence of $26 \%$ in Brown $S$ et al. [13] and the lowest incidence was noted in Cheng $\mathrm{K}$ et al. [14] of about 3.34\%.

The majority of the patients who underwent surgery in this study had a mean age of 29.1 years and were males accounting for $72 \%$ of the total patients as compared to mean patient age of 54.62 (range 2-92) years and 542 males and 596 females in Cheng $\mathrm{K}$ et al. [14]. The length of stay was not considered to contribute to the outcome of surgical wounds in that study, but was considered to be contributing to the outcome in our study. Our study and that undertaken by Cheng $\mathrm{K}$ et al. [14], both showed increased risk of SSIs in patients having co-morbidities. The OR for contaminated-dirty to clean and cleancontaminated wounds was $11.02(\mathrm{CI}=7.69-15.79)$. The $\mathrm{OR}$ for wound drain use was $3.46(\mathrm{CI}=2.49-4.80)$, and the percentage of patient with SSIs with wound drainage and without drainage was 3.6\% in our study. The level of education also had a positive impact on the outcome of the surgical procedure in this study. The OR for study participants having more than 12 years education was 0.37 ( $\mathrm{CI}=0.23-$ $0.61)$ as compared to $0.99(\mathrm{CI}=0.66-1.46)$ for those $9-12$ education years and $1.36(\mathrm{CI}=0.98-1.90)$ for those with education less than 9 years. Females were more prone to SSIs as compared to males with incidence of $55.7 \%$ in females and $44.3 \%$ in males. The risk for SSIs was increased in diabetic as compared to non-diabetic patients in our study group $(\mathrm{OR}=1.36, \mathrm{CI}=0.98-1.90)$ and diabetes was also found to be a risk factor for SSIs in Cheng $\mathrm{K}$ et al. study group ( $\mathrm{OR}=6.400$, $\mathrm{CI}=2.582-15.866$ ). The use of pre-op antibiotics was not effective in decreasing the SSIs incidence in this study with OR of 1.33 (CI=0.901.98). The OR for patients admitted to ICU was $5.87(\mathrm{CI}=4.17-8.25)$ showed higher risk for SSIs for ICU patients. The most common SSIs causative organism was Staphylococcus aureus (25\% incidence) followed by Eschershia coli (23\% incidence) in this study as compared to Eschershia coli (34\% incidence), and Pseudomonas aeruginosa (26\% incidence) in Khairy GA et al. [6] study. The longer duration of surgery also seemed to cause more SSIs incidence. The ASA score of 3 or greater than was considered to be a significant risk for SSIs in our study group and this is also shown in other studies like that of Cheng K et al. [14], Khan $\mathrm{M}$ et al. [15] and Wloch C et al. [16]. There was no readmission for SSIs in our study however the percentage of readmission for SSIs was $0.6 \%$ for women who underwent Caesarian sections in Wloch et al. [16]. Their incidence was $9.6 \%$ as compared to $11.4 \%$ in our study; however this difference can be due to the specific type of surgical procedures that are carried out (e.g. women who underwent caesarian sections). The risk of SSIs was increased in Wloch et al. [16] study patients, where the surgery was done by staff grade surgeons or associate specialists however our study does not provide any such data for comparison. Another study carried out by Motie MR et al. [3] with a mean age of 47.13 years with a SD of 19.60 years for the study group showed that most infections were cleancontaminated $(46.3 \%$ ) and $30.5 \%$ contaminated as compared to $27.9 \%$ clean-contaminated and $43.1 \%$ contaminated in our study group. The length of surgery and type of surgery were found to increase the risk of SSIs in their study which is consistent with the results of our 
Citation: Rawabdeh AAA, Al Mulhim ARS, Khan ZU (2016) Surgical Site Infections Incidence, their Predictors and Causative Organisms in a Teaching Hospital Int J Community Fam Med 1: 104. doi: https://doi.org/10.15344/2456-3498/2016/104

Page 6 of 6

study group. Devjani D et al. [17] study group carried out on women undergoing lower segment caesarian section showed an infection rate of $24.2 \%$ and the most common microorganism isolated was Acinetobacter (32.03\%) followed by Escherichia coli and Klebsiella species responsible for $18.75 \%$ and $14.8 \%$ of SSIs, respectively. This is in contrast to our study where Staphylococcus was the main causative microorganism with incidence rate of SSIs caused by it was $25.7 \%$ and the overall incidence of SSIs was about $11 \%$. Length of surgical procedure was a risk factor and was associated with higher incidence of SSIs in Devjani D et al. [17] and was confirmed in our study group as well. The incidence of SSIs was increased in their study group patients who received antibiotics earlier than 2 hours whereas antibiotics were not associated with the outcome in our study group. This study concluded, SSIs are a major problem in the surgical wards of KFH. Co-morbid conditions like diabetes, hypertension and the length of hospital stay and level of education which can be related to awareness and site and type of operation plays a major role in SSIs. Pre-operative antibiotics do not seem to be effective in this study. A better surveillance and reporting system of SSIs is recommended to decrease the risk of SSIs which would increase patient health outcome and in turn, be cost effective. It is recommended that administration in $\mathrm{KFH}$ should employ more preventive measures (for example, proper hand hygiene before and after contact with patients, effective aseptic techniques and disinfection of materials and to prompt removal of catheters that are no longer essentials to prevent occurrence of NCIs). Large number of patients were admitted to the surgical sites at $\mathrm{KFH}$, and especially to ICU, with average daily census of 140 patients whom are at risk of acquiring NCIs. Great effort has been spent to generate more data over the cost escalations, in terms of increase in the length of stay (excess days of stay), medications and time of health workers, but unfortunately the researchers were not successful.

\section{Recommendations}

This article recommended proper nursing care, sterilization and disinfection of instruments and equipment with careful handling of intensive procedures to control such life threatening infections in efficient and effective manners. Traditional and automated (recommended) surveillance surgical sites infections systems should work effectively to reduce incidence and prevalence rates of SSIs to minimum levels based on international standards (incidence $=6 \%$, prevalence $=18 \%$ ). Since most infections become manifest after discharge where patient with infections rarely return to $\mathrm{KFH}$, the traditional methods of surveillance become insufficient, if not inaccurate. Therefore, an automated post-discharge surveillance method for SSIs in addition to the traditional method employed within the entire hospital is highly recommended to generate a better picture of SSIs at KFH which would improve the overall quality of care provided by staff. There are also many possibilities for researchers to compare infection rates within and across the hospital words. However, such opportunities require more cooperation from the hospital management and other authorities.

\section{Competing Interests}

The authors declare that they have no competing interests.

\section{References}

1. Campbell RS, Emons MF, Mardekian J, Girgenti D, Gaffney MH (2015) Adverse clinical outcomes and resource utilization associated with methicillin-resistant and methicillin-sensitive Staphylococcus aureus infection after elective surgery. Surg Infect (Larchmt) 16: 543-52.
2. Ramirez-Wong FM, Atencio-Espinoza T, Rosenthal VD, Ramirez E, TorresZegarra SL, et al. (2015) Surgical site infections in more than 13,000 surgical procedures in three cities in Peru: Findings of the International Nosocomial Infection Control Consortium. Surg Infect (Larchmt) 16: 572576.

3. Motie MR, Ansari M, Nasrollahi HR (2014) Assessment of surgical site infection risk factors at Imam Reza hospital, Mashhad, Iran between 2006 and 2011. Med J Islam Repub Iran 28: 52.

4. Cheng K, Li J, Kong Q, Wang C, Ye N, et al. (2015) Risk factors for surgical site infection in a teaching hospital: a prospective study of 1,138 patients. Patient Prefer Adherence 9: 1171-1177.

5. Emori TG, Culver DH, Horan TC, Jarvis WR, White JW, et al. (1991) National nosocomial infections surveillance system (NNIS): description of surveillance methods. Am J Infect Control 19: 19-35.

6. Khairy GA, Kambal AM, AI-Dohayan AA, Al-Shehri MY, Zubaidi AM, et al. (2011) Surgical site infection in a teaching hospital: A prospective study. J T U Med Sc 6: 114-120.

7. Horan TC, Gaynes RP, Martone WJ, Jarvis WR, Emori TG (1992) CDC definitions of nosocomial surgical site infections, 1992: a modification of $\mathrm{CDC}$ definitions of surgical wound infections. Infect Control Hosp Epidemiol 13: $606-608$.

8. Mangram AJ, Horan TC, Pearson ML, Silver LC, Jarvis WR (1999) Guideline for Prevention of Surgical Site Infection, 1999. Centers for Disease Control and Prevention (CDC) Hospital Infection Control Practices Advisory Committee. Am J Infect Control 27: 97-132.

9. Nagelkerke NJ (1991) A note on a general definition of the coefficient of determination. Biometrika 78: 691-92.

10. Lilani SP, Jangale N, Chowdhary A, Daver GB (2005) Surgical site infection in clean and clean-contaminated cases. Indian J Med Microbiol 23: 249252.

11. Shahane V, Bhawal S, Lele U (2012) Surgical site infections: A one yea prospective study in a tertiary care center. Int J Health Sci (Qassim) 6: 79-84.

12. Atif ML, Bezzaoucha A, Mesbah S, Djellato S, Boubechou N, et al. (2006) [Evolution of nosocomial infection prevalence in an Algeria university hospital (2001 to 2005)]. Med Mal Infect 36: 423-428.

13. Brown S, Kurtsikashvili G, Alonso-Echanove J, Ghadua M, Ahmeteli L, et al. (2007) Prevalence and predictors of surgical site infection in Tbilisi, Republic of Georgia. J Hosp Infect 66: 160-166.

14. Cheng K, Li J, Kong Q, Wang C, Ye N (2015) Risk factors for surgical site infection in a teaching hospital: a prospective study of 1,138 patients. Patient Prefer Adherence 9: 1171-1177.

15. Khan M, Yousaf M, Wadood A, Junaid M, Ashraf M, et al. (2014) Discovery of novel oxindole derivatives as potent a-glucosidase inhibitors. Bioorg Med Chem 22: 3441-3448.

16. Wloch C, Wilson J, Lamagni T, Harrington P, Charlett A, et al. (2012) Risk factors for surgical site infection following caesarean section in England: results from a multicentre cohort study. BJOG 119: 1324-1333.

17. De D, Sexena S, Mehta G, Yadav R, Dutta R (2013) Risk Factor Analysis and Microbial Etiology of Surgical Site Infections following Lower Segment Caesarean Section. International Journal of Antibiotics, 283025 